\title{
LOS NEGOCIOS DE UNA GRAN EMPRESA SEDERA EN LA VALENCIA DEL SIGLO XVIII: LA COMPAÑÍA DE NUESTRA SEÑORA DE LOS DESAMPARADOS
}

\author{
RICARDO FRANCH BENAVENT \\ Universidad de Valencia
}

\section{RESUMEN}

La Compañia de Nuestra Señora de los Desamparados fue creada por el artesanado sedero en 1772, pero la Junta General de Comercio cambió su naturaleza al autorizar la participación en su accionariado de todas las clases sociales. Aunque esta circunstancia favoreció su desarrollo, sentó también las bases de su fracaso final al provocar un grave conflicto entre el sector artesanal, que ejercia en exclusiva los cargos directivos, y el resto del accionariado, siendo el motivo fundamental de la discordia las perdidas sufridas durante la crisis comercial de 1779-82. De todas formas, la conservación de su documentación privada ha permitido analizar su actividad manufacturera y los resultados de sus negocios, entre los que destacó la comercialización de los tejidos de seda en Cädiz.

\section{ABSTRACT}

The "Compañia de Nuestra Señora de los Desamparados" was made by the silk craftsmen in 1772, but the General Board of Commerce changed its nature to authorize all the social classes to take part in share-holders. Although that circumstance favoured its growth, it laid the foundations of its final failure to provoke a serious conflict between the craftsmen sector, who exercised sole right the managines charges, and the rest of share-holders, which fundamental discord motive was the loss suffered in the commercial crisis of 1779-82. Anyway, the preservation of its private documentation has made it possible to analyse its manufacturing activity and the result of its business; the commercialization of the silk textile in Cádiz stands out. 


\section{INTRODUCCION: EL SURGIMIENTO DE UN PROYECTO DE CARÁCTER ARTESANAL 1}

La expansión experimentada por la sederia valenciana dieciochesca favoreció la intervención del capital comercial en la actividad productiva, sin que la reglamentación gremial existente en la ciudad de Valencia impidiese el desarrollo del «Verlagssystem». Esta evolución fue reforzada por la propia diferenciación social que se estaba produciendo en el mundo artesanal, y que se materializaba en la aparición de un sector de maestros del arte mayor de la seda que asumia funciones empresariales y controlaba la actividad de otros compañeros de oficio. En conjunto, ambos grupos controlaban entre el 70 y el $80 \%$ de los telares activos registrados en sendos documentos de 1738 y 1771 que se han localizado recientemente, lo que revela que el nuevo sistema de organización de la producción podia estar más difundido de lo que apuntó V. Martínez Santos, quien estimaba que afectaba a la tercera parte de los telares activos en la década de 1760. En todo caso, lo cierto es que la expansión de la sederia estaba favoreciendo la consolidación de una acaudalada burguesia que centraba sus negocios en la producción y comercialización de los tejidos de seda, lo que amenazaba seriamente la independencia económica del artesanado tradicional 2. Realmente, esta situación resultaba cada vez más dificil de sostener, puesto que eran muchos los factores que debilitaban la posición de los maes-

1 En la presente introducción se recogen algunas de las ideas fundamentales de un trabajo mas amplio ( $₫ \Lambda$ rtesanado sedero y capital comercial en la Valencia del siglo xvilim, que se halla en vias de publicación) sobre el desarrollo del "Verlagssystem» en la sederia valenciana dieciochesca, las iniciativas de carácter defensivo adoptadas por el artesanado y las circunstancias que enmarcaron la creación de la Compañia de Nuestra Señora de los Desamparados. Lo poco que se conocia de esta última hasta el momento esta sintetizado en Martinez Santos (1981), pp. 105. 111. También V. Ribes Iborra utilizo someramente su correspondencia comercial con los factores gaditanos para ilustrar las caracteristicas basicas del comercio sedero con América. Ver Ribes (1985), pp. 61-92. Por mi parte, ya realicé una primera aproximacion a los negocios de la compañia con su corresponsal Diego Lostau entre 1776 y 1779 en Franch (1994 a), pp. 650-658. Para una mejor comprensión del presente trabajo cabe tener en cuenta las siguientes equivalencias: 1 libra valenciana $=20$ sueldos $=10$ reales valencianos $=15$ reales y 2 maravedis de vellon. En la documentación se otorga una equivalencia de 8 reales de plata por cada libra valenciana. La libra de 12 onzas tenia un peso de $0,355 \mathrm{Kg}$. Por su parte, la vara valenciana tenia una extensión de 0,906 metros, mientras que la castellana equivalia a 0,835 metros. Vidal y Polo (1862), pp. 17 y 54. A pesar de ello, en la documentación analizada se incrementan las varas valencianas en un $6 \%$ para convertirlas en castellanas (ver cuadro num. 5).

? Sobre el comercio valenciano dieciochesco y la consolidación de la burguesia sedera, ver Franch (1986 y 1989 a). La estimación sobre la difusión del "Verlagssystem" en la década de 1760, en Martinez Santos (1981), p. 120. Los documentos de 1738 y 1771 citados en el texto, que son estudiados con mas detenimiento en el trabajo en prensa aludido en la nota anterior, se hallan en A.M.V. (Archivo Municipal de Valencial. Gremios en general. Caia 7. Exp. num. 11; y A.C.A.M.S.V. (Archivo del Colegio del Arte Mayor de la Seda de Valencial. Sig. 3.5.2. Leg. 7. 
tros del arte mayor de la seda. Aparte de la mayor eficiencia y de las facilidades en la conexión con el mercado que comportaba el nuevo sistema productivo, los artesanos modestos experimentaban grandes dificultades en el abastecimiento de materias primas. Hay que tener en cuenta que éstas derivaban de una producción agricola que tendió hacia el estancamiento y el declive desde mediados de la centuria, y que, en todo caso, era muy sensible a los fenómenos meteorológicos. Asi, además de cosechas catastróficas, como fue el caso, por ejemplo, de las de 1763 y 1771, eran bastante frecuentes los años de producción mediocre. El problema se agravaba cuando la monarquia autorizaba la exportación de la materia prima. Aunque ello fue objeto de encendidas polémicas y acabaron triunfando las tesis prohibicionistas, hubo periodos en que aquélla adquirió una cierta continuidad, como ocurrió durante buena parte de la década de 1760 al amparo del famoso decreto de 15 de mayo de dicho año. $\mathrm{Y}$ a todas estas dificultades se añadía el marcado carácter estacional que tenía la comercialización de la seda, elevándose los precios y agudizándose su escasez en los meses más alejados de la cosecha ${ }^{3}$.

Los artesanos tomaron pronto conciencia de la necesidad de reaccionar en defensa de su independencia económica, y a partir de la década de 1740 se sucedieron las iniciativas tendentes a reforzar su cooperación y favorecer la actividad de sus propios talleres. Sus objetivos básicos eran claramente defensivos: trataban de lograr un abastecimiento regular de materias primas; y aspiraban, sobre todo, a poder mantener ininterrumpidamente su actividad, sin que ésta se viese periódicamente amenazada por la escasez o carestia de la materia prima o por las fluctuaciones de los pedidos de los empresarios sederos. Las primeras tentativas conocidas ya se encaminaron a la constitución de grandes compañias por acciones que integrasen a la mayoría de los artesanos. Aunque estos ambiciosos proyectos fracasaron, tal vez impulsaron al propio colegio del arte mayor de la seda a adoptar una iniciativa en la misma linea, pero con objetivos más modestos. De esta forma, se constituyó un pósito destinado a favorecer el abastecimiento de materias primas por parte de las fábricas, que comenzó a operar a partir de 1757. Su actividad se fue consolidando, pero los modestos artesanos consideraban que resultaba insuficiente para evitar su creciente empobrecimiento, y más en una coyuntura de constantes dificultades como la década de 1760. En este marco, la mala cosecha de 1771 actuó como un precipitante. La paralización de las fábricas fue tan intensa que en la visita efectuada por el colegio del arte mayor de la seda en febrero de 1772 se regis-

3 Sobre la evolucion de la producción de seda, la polemica sobre su exportación y la estacionalidad en su comercialización, ver respectivamente, Franch (1994 b, 1989 b y 1990 ). 
traron 2.436 telares parados de los 3.598 existentes. $Y$ de ahi que en abril del mismo año 20 maestros interpusiesen ante el tribunal de intendencia una demanda judicial que trataba de forzar a la corporación gremial a patrocinar la constitución de una compañia por acciones. Todo parece indicar que este fue el germen de la creación de la Compañia de Nuestra Señora de los Desamparados.

En un principio, la compañia tenía un carácter exclusivamente artesanal. Según los capitulos iniciales que debian regir su actividad, que fueron elaborados el 23 de septiembre de 1772, solamente podian participar en ella los maestros del colegio del arte mayor de la seda o sus familiares más directos (viudas e hijos). En consonancia, el valor de las acciones con las que debia reunirse el capital se estipuló en 20 libras. Y, a pesar de ser una cifra tan modesta, se dispuso la posibilidad de que los maestros pudiesen aportar dicho capital en el plazo de un año. No obstante, el colegio del arte mayor de la seda anunció su intención de invertir en acciones 8.382 libras procedentes del fondo del pósito para el abastecimiento de materias primas que se habia creado en 1757. Tal vez por ello, y porque era la corporación en la que se integraban profesional. mente los accionistas y que habia dado el impulso definitivo al proyecto, se otorgó al colegio una participación institucional en el principal órgano directivo de la sociedad. En efecto, el mayoral del colegio formaria parte de la Junta de Dirección al lado del director general y de dos subdirectores, además de los cargos administrativos (secretario, contador y tesorero) que, a diferencia de los anteriores, no dispondrian de derecho a voto. $Y$, además, se estipuló que sería en los propios locales del colegio en donde se reunirian los organos directivos y en donde se ubicaria la tesorería y el depósito general de la compañia. Por canto, ésta se hallaba estrechamente vinculada a la corporación sedera, hasta el punto de que, ademas de su nombre institucional, fue conocida también como la compañia de los maestros del colegio del arte mayor de la seda de Valencia.

Sin embargo, la naturaleza de la compañia fue radicalmente transformada por las modificaciones impuestas por la Junta General de Comercio para proceder a su aprobación t. Fueron ellas las que permitieron el éxito inicial de la compañia, al eliminar su carácter artesanal y autorizar la participación en el accionariado del resto de los grupos sociales. De esta forma, como luego veremos, se llegaron a suscribir acciones por un valor total de 193.325 libras, lo que permitió acrecentar la actividad efectuada por el antiguo pósito al superar

+ Los capítulos iniciales de la compañia y las modificaciones impuestas por la Junta General de Comercio pueden verse en B.U.V. (Biblioteca Universitaria de Valencia). Sig. F-301. Folleto núm. 5. 
ampliamente las adquisiciones anuales de seda las 14.000 libras de 12 onzas en la segunda mitad de la década de 1770 . Se trata de una cifra importante, aunque sólo representa entre el 3 y el $4 \%$ de la seda comercializada en el «contraste» a finales de la centuria. Pero, además, la compañia se fue introduciendo también en el negocio manufacturero, controlando el trabajo de unos 50 telares y llegando a producir alrededor de 40.000 varas anuales de tejidos de seda a finales de la década de 1770 . De nuevo, las cifras son relativamente modestas, ya que sólo podrian representar alrededor del $1,5 \%$ de los telares registrados en la ciudad de Valencia y del 2 al $3 \%$ de la producción total s. Pero lo destacable es que el proyecto impulsado por el artesanado se estaba consolidando y disponia de un capital equiparable al patrimonio de cualquiera de los grandes comerciantes de la ciudad de Valencia. Sin embargo, su trayectoria se quebró debido a la contraposición de intereses de los diversos sectores que acabaron constituyendo su accionariado. Puesto que, a pesar de su apertura al conjunto de las clases sociales, la compañia continuó manteniendo numerosas facetas del proyecto artesanal inicial, como era el caso, sobre todo, de la exclusividad de que gozaban los maestros del arte mayor de la seda en la ocupación de los cargos directivos. Fue este uno de los factores fundamentales que acabaron determinando su fracaso final.

\section{LA TRANSFORMACIÓN DE LAS BASES SOCIALES DE LA COMPANIÍA Y LA EVOLUCIÓN GENERAL DE LOS RESULTADOS DE SUS NEGOCIOS}

El proyecto elaborado por los artesanos sederos fue contemplado con mucho recelo por parte de la burguesia sedera y los organismos centrales de la monarquia. Aquélla temia, sobre todo, la competencia que la compañia podia ejercer a la iniciativa privada en las actividades de elaboración y comercialización de los tejidos. De ahi que centrase sus esfuerzos en limitar los negocios de la nueva sociedad al ámbito del abastecimiento de materias primas a las fábricas, convirtièndola en una mera continuadora del pósito del colegio. En un principio lograron su objetivo, ya que la orden de la Junta General de Comercio de 30 de julio de 1773 daba su visto bueno al proyecto de los artesanos con la reserva expresa de que no se pudiese intervenir en la fábrica y cl comercio de tejidos de seda. Sin embargo, el recurso planteado por los directores

'La evolucion del numero de telares de la ciudad de Valencia y las estimaciones sobre la producción total a finales de la centuria pueden verse en Martinez Santos (1981), pp. 144 y 147. Sobre la seda comercializada en cl «contraste”, ver Franch (1990). 
de la compañía determinó que esta limitación se revocase en la nueva orden del 2 de diciembre de 1773. De esta forma, se abria la posibilidad de que la compañia adquiriese un claro carácter empresarial. Realmente, la Junta General de Comercio estaba más preocupada por evitar que el proyecto siguiera el mismo camino que habian descrito ya numerosas iniciativas artesanales de la misma indole, dando origen a grandes compañias que carecian de sólidas bases financieras y que, por tanto, se desmoronaban con gran rapidez. Asi estaba ocurriendo en esos mismos momentos, por ejemplo, con la Compañia de la Real Fábrica de Paños Superfinos de Segovia t. De ahi que la orden de 30 de julio de 1773 considerase insuficiente el fondo de 22.000 pesos que los artesanos sederos alegaban haber reunido. $Y$, calculando que el proyecto requeriría un capital de 500.000 a 600.000 pesos para ser viable, dispuso que «... se admitan acciones no sólo de los maestros del colegio, sino de qualesquiera particulares...». Ahora bien, esta ampliación de las bases sociales del accionariado se consideró compatible con la reserva de los cargos directivos para los artesanos sederos, sin tener en cuenta los problemas que ello podia ocasionar. Ya que en la Junta General de Accionistas el voto dependia directamente del numero de acciones poseidas, sin existir ninguna discriminación en favor de los artesanos que les garantizase el control absoluto de la sociedad. El valor de las acciones también fue incrementado, fijándose en 50 libras, aunque admitiéndose la posibilidad de adquirir medias acciones de 25 libras. Y cada voto en la Junta General se vinculó a la posesión de cuatro acciones, limitándose, no obstante, a cinco el número máximo de votos que podia poseer cada accionista. En estas condiciones, era previsible que el peso de los artesanos en la base social de la compañia se redujese considerablemente, ya que su escaso poder económico les permitiria disponer de un número muy limitado de votos. Asi se desprende claramente del análisis del proceso de suscripción de acciones.

Iniciada en octubre de 1773, la suscripción de acciones tuvo lugar a un ritmo muy lento en los dos primeros años de actividad, hasta el punto de que en octubre de 1775 sólo se había logrado reunir un capital de 37.150 libras. Fue a partir de entonces cuando el proceso se aceleró sustancialmente, llegando a su punto más álgido en el ejercicio 1776-77, en el que se adquirieron acciones por valor de 65.350 libras, lo que suponia doblar prácticamente el capital suscrito hasta el momento (que ascendia a 68.500 libras). A partir de entonces, el crecimiento fue muy moderado, retrayéndose totalmente a partir de la crisis experimentada en 1780 como consecuencia de la guerra entablada en contra de Inglaterra. No obstante, el éxito que habia obtenido la compañia hasta

\footnotetext{
- Garcia Sanz (1977), pp. 229.231.
} 


\section{CUADRO 1}

Condición social de los accionistas de la Compañia de Nuestra Señora de los Desamparados (valores expresados en libras valencianas)

\begin{tabular}{|c|c|c|c|c|}
\hline Condic social & Num acc. & Capital & $o_{*}$ & Cap medio \\
\hline Noble & 3 & 20.400 & 10,55 & $6.800,00$ \\
\hline Comerciante ... & 4 & 7.675 & 3,97 & $1.918,75$ \\
\hline Prof y rentistas acom. & 60 & 61.875 & 32,01 & $1.031,25$ \\
\hline Eclesiásticos .......... & 37 & 25.300 & 13,09 & 683,78 \\
\hline Varón sin tratamicnto & 61 & 24.925 & 12,89 & 408,61 \\
\hline Mujer sin tratamiento $\ldots \ldots \ldots$ & 61 & 24.175 & 12,50 & 396,31 \\
\hline Maestro sedero ............... & 91 & 17.125 & 8.86 & 188,19 \\
\hline Colegio arte mayor ............ & 1 & 9.825 & 5.08 & 9.825 .00 \\
\hline Otros artesanos $\ldots \ldots \ldots \ldots \ldots$ & 16 & 2.025 & 1,05 & 126,56 \\
\hline Total. & 334 & 193.325 & 100 & 578,82 \\
\hline
\end{tabular}

Fur.tr: Libro de acciones de la compañia. A.C.A.M.S.V. Sig. 2.3.1. Libro 2.

estos momentos era manifiesto, puesto que se habian llegado a suscribir acciones por un valor total de 193.325 libras, procediendo el capital de un amplio abanico de grupos sociales ${ }^{7}$. Asi se desprende claramente del análisis del cuadro n." 1, que permite distinguir la existencia de tres grandes grupos de similar entidad en cuanto a sus efectivos totales pero cuyas aportaciones eran de una magnitud muy diferente.

El primero de los grupos aludidos estaba integrado por las clases rentistas y acomodadas, siendo sus componentes tres miembros de la nobleza titulada, 4 comerciantes, 60 «profesionales» y personas distinguidas con el tratamiento de «Don», y 37 eclesiásticos. Eran ellos los que podian controlar perfectamente la compañía, puesto que, aunque sólo constituian el $31,13 \%$ de los accionistas, acaparaban el 59,62\% del capital suscrito. Entre sus miembros se encontraban los accionistas más importantes, siendo perfectamente significativo el hecho de que el capital medio de cada uno de sus sectores fuese superior a

El proceso de suscripcion de acciones se halla registrado en el libro de acciones de la compañia, que se conserva en A.C.A.M.S.V. Sig. 2.3.1. Libro 2. El analisis de la condición social de los accionistas se ha efectuado partiendo de sus titulares iniciales, sin tener en cuenta las modificaciones que se pudieron producir ulteriomente. Estas fueron muy escasas, por lo que dificilmente pudieron alterar de forma sustancial la estructura resultante. Segun consta en el libro de deliberaciones de la compañia (conservado en el mismo archivo. Sig. 2.3.1. Libro 21), las transacciones sólo se produjeron entre 1778 y 1780 , siendo lo mas habitual que se amortizase el capital al recurrir la compañia al derecho de tanteo. 
la media general. Las inversiones más fuertes fueron las realizadas por los tres miembros de la nobleza titulada. Uno de sus miembros era precisamente el mayor accionista de la compañia: se trataba de la condesa de Cirat y Villafranqueza, que llegó a adquirir acciones por un valor total de 10.000 libras, con lo que acaparaba por si sola el $5,17 \%$ del capital total 8 . También a la nobleza titulada pertenecia el tercer mayor accionista de la compañia: la marquesa de la Mina, que adquirio acciones por valor de 8.000 libras. Finalmente, el otro miembro de este sector social era el marqués de Almunia, cuya inversión ascendió a 2.400 libras. Aunque la participación nobiliaria en el accionariado al. canzó una cierta relevancia, resulta dudoso que ello se pueda insertar en la tendencia descrita en otros paises en favor de una creciente participación de la nobleza en el mundo de los negocios, de la que se han encontrado muy pocos indicios en España. Circunstancias muy particulares pudieron influir en la decisión de las tres casas aludidas, y más teniendo en cuenta que las dos primeras estaban relacionadas por vinculos de parentesco y que acababan de recibir una buena parte de la herencia del conde del Real ${ }^{9}$. Más reducida fue, en cambio, la participación del mundo comercial, evidenciando la hostilidad con que este sector social contempló la creación de la compañia. Sólo cuatro comerciantes se interesaron en ella, aunque la inversión sólo alcanzó una cierta relevancia en los casos de Juan Bautista Boneli, con 5.000 libras, y Juan Ángel de Llano, con 2.000. Se trata, en ambos casos, de grandes comerciantes que efectuaban unos negocios muy diversificados ${ }^{10}$. En todo caso, resulta llamativa la completa ausencia de la gran burguesia sedera, muy preocupada por la competencia que podia ejercer la compañia a su actividad particular. Más frecuente e importante fue la participación del sector que se ha calificado como «profesionales y rentistas acomodados». Realmente, el grueso de sus componentes está integrado por las 51 personas de las que únicamente contamos con la re-

* Para calibrar la entidad de la inversion, hay que tener en cuenta que el 60 of de las casas nobiliarias valencianas estudiadas por $\mathrm{J}$. A. Catala tenian unos ingresos anuales inferiores a dicha cifra, y que el propio conde de Cirat obtuvo en 1766 unas rentas de 11.818 libras. Ver Catala (1995). pp. 16-17.

"Catala (1995), p. 19. La distribución de la herencia del conde del Real, una de las casas más acaudaladas de la nobleza valenciana, se habia realizado en $1767, \mathrm{y}$, aparte de diversos vínculos, la condesa de Cirat y la marquesa de la Mina recibieron, respectivamente, 36.380 libras proce. dentes de los bienes libres. Agradezco a J. A. Catalá que me facilitara esta información. Sobre la creciente intervención de la nobleza en el mundo de los negocios, puede verse, por ejemplo, Richard (1974). Ver tambien Chaussinand-Nogaret (1984).

13. Juan Bautista Boneli era un enriquecido hombre de negocios de origen genovés que se vinculó matrimonial y comercialmente con la dinastia Vague. Juan Angel de Llano fue el primer director de la fábrica de tejidos de seda que establecieron los Cinco Gremios Mayores de Madrid en Valencia, pero efectuaba particularmente unos negocios de caracter muy diversificado. Ver Franch (1989 a), pp. 202-206. 
ferencia de su tratamiento como «Don», lo que revelaba la pertenencia a un estatus económico relativamente elevado. Lo cierto es que la inversión media que realizaron, que ascendia a 1.080 libras, superaba ampliamente la del conjunto de los accionistas. En la misma linea se situan los 9 «profesionales» $(2 \mathrm{mi}$ litares, 2 abogados, 2 escribanos, 1 funcionario, 1 médico y 1 escultor) que se han incluido junto a ellos. Este sector tenia, pues, un peso muy importante en la compañia, al acumular el 32,01\% del capital total. Relativamente elevada fue también la inversión efectuada por los eclesiásticos, representados por 28 presbiteros y 9 religiosos, que acumularon algo mas del $13 \%$ del capital. En su conjunto, los componentes de los diversos sectores abordados, que disponian de suficientes acciones para controlar la compañia, debieron de interesarse en ella con el objetivo básico de obtener unos ingresos adicionales, por lo que dificilmente serían sensibles a la consecución de otros fines que resultasen beneficiosos para las fábricas pero que pudiesen erosionar los beneficios. Por tanto, sus intereses se hallaban muy alejados de las aspiraciones iniciales que impulsaron a los artesanos a constituir la compañia, lo que podia propiciar el desencadenamiento de un grave conflicto.

Algo similar se podria decir del segundo gran grupo que se distingue en el accionariado y que englobaría a todas las personas de las que sólo se conoce su nombre y que no reciben ningún tratamiento de distinción. Su condición económica parece claramente inferior a la de los sectores aludidos anteriormente, siendo significativo que su inversión media se sitúe en torno a las 400 libras. También es revelador el carácter numeroso del grupo, que englobaba al $36,52 \%$ de los accionistas, a pesar de lo cual sólo controlaban el 25,39\% del capital. Otra circunstancia que merece la pena destacar es que la mitad de sus componentes era de sexo femenino, lo que refuerza la impresión del carácter rentista que debieron de tener sus inversiones. Realmente, la Compañia de Nuestra Señora de los Desamparados contó en su accionariado con una participación femenina bastante elevada. Si a las 61 mujeres aludidas se añaden las 22 que reciben el tratamiento de «Don» y las dos pertenecientes a la nobleza titulada, su proporción llegaba al 25,45\% de los accionistas, pero acumulando el $32,58 \%$ del capital. No cabe duda que tanto ellas como el resto de los sectores aludidos no debieron efectuar sus inversiones con la pretensión esencial de fomentar el desarrollo de la manufactura sedera.

Este ultimo objetivo solo tendria una mayor incidencia en el sector propiamente artesanal del accionariado. Se trataba de un grupo bastante numeroso, puesto que constituía el $32,33 \%$ de los efectivos totales. Pero, al disponer de un poder económico muy modesto, sólo lograban controlar el 14,99\% del capital. Y ello incluyendo las 9.825 libras que finalmente invirtió el colegio en ac- 
ciones. Es decir, los artesanos considerados individualmente no fueron capaces de suministrar más que el $9,91 \%$ del capital total de la compañia. La mayoria estaba constituida por maestros del colegio del arte mayor de la seda, que realizaron una inversión media de 188 libras, muy por debajo de la media general de 578 libras. La reiterada acusación de falta de capitales que se lanzaba en contra del artesanado desde los sectores de los cosecheros y exportadores de seda " parece confirmarse plenamente, puesto que sus miembros fueron incapaces de lograr una intensa participación en el principal proyecto que ellos mismos impulsaron para favorecer el desarrollo de la manufactura. El fenómeno resulta aún más evidente si se tiene en cuenta que sólo en seis casos la inversión fue superior a la media general aludida (578 libras). Algunos de ellos eran destacados fabricantes que acabarian integrándose en la burguesía sedera. Pero lo más frecuente entre los que se hallaban en esta misma situación es que la inversión fuese mucho más reducida. Es decir, el sector más enriquecido del artesanado sedero no apostó decididamente en favor de la compañia. Realmente, al haber surgido con el objetivo de mantener ininterrumpidamente la actividad de las fábricas, era a los artesanos más modestos a quienes más interesaba el éxito del proyecto. Pero como su patrimonio era muy reducido, dificilmente podian realizar una inversión considerable. Resulta significativo, en este sentido, que 26 de los 91 maestros sederos adquiriesen sólo media acción, y otros 17 se limitasen a hacer una inversión de 50 libras. Es decir, casi la mitad de los miembros del colegio del arte mayor de la seda que participaron en la compañia sólo fueron capaces de aportar el capital mínimo que se requería en sus estatutos. En la misma linea se situó la intervención de los restantes sectores artesanales. Su inversión media fue la más baja de todos los grupos analizados, cifrándose en 126 libras. Su número tampoco fue muy considerable, ascendiendo únicamente a 16 , la mitad de los cuales eran maestros tintoreros. Realmente, la compañia, que habia surgido como un proyecto exclusivamente artesanal, no logró contar con una intensa presencia de este sector social entre su accionariado. Probablemente fuesen sus escasos recursos los que lo impidiesen. Lo cierto es que si la compañia se hubiese mantenido en sus límites originales habria estado condenada a una existencia muy precaria. Si logró alcanzar una entidad considerable fue gracias a la apertura a los restantes sectores sociales impuesta por la Junta General de Comercio.

11 La polémica entre ambos grupos en la primera mitad de la centuria puede verse en Martinez. Santos (1981), pp. 48.62. Su continuación en la segunda mitad de la centuria, en Franch (1989b), pp. $51-81$. 


\section{CUADRO 2}

Evolución de los resultados de la Compañia de Nuestra Señora de los Desamparados (valor expresado en libras valencianas)

\begin{tabular}{|c|c|c|c|}
\hline Ejercicio & Resultudo & or capital & $\omega_{0}^{\infty}$ dividendo \\
\hline 1773.74 & $1.691,00$ & 8,43 & n. d. \\
\hline 1774.75 & $2.224,75$ & 7,07 & 7,07 \\
\hline $1775.76 \ldots \ldots \ldots \ldots$ & $5.782,47$ & 10,45 & 10,45 \\
\hline $1776-77$ & $6.122,93$ & 6,26 & 6,26 \\
\hline $1777.78 \ldots$ & $6.589,55$ & 4,39 & 4,39 \\
\hline $1778.79 \ldots$ & $11.960,72$ & 6,93 & 6,93 \\
\hline $1779.80 \ldots \ldots \ldots \ldots$ & $-3.813,42$ & $-2,14$ & 0,00 \\
\hline $1780.81 \ldots \ldots \ldots \ldots$ & n. d. & n. d. & 0,00 \\
\hline $1781-82 \ldots \ldots \ldots \ldots$ & $2.200,82$ & 1,37 & 2,00 \\
\hline $1782.83 \ldots \ldots \ldots \ldots$ & 9.722 .14 & 6,33 & 3,00 \\
\hline 1783.84 & n. d. & n. d. & 5,00 \\
\hline
\end{tabular}

Nota: n.d. $=$ no disponible.

Fuexte: Libro de deliberaciones de la compañia. A.C.A.M.S.V. Sig. 2.3.1. Libro 21. La información de los ultimos años procede de diversas certificaciones del secretario. A.C.A.M.S.V. Sig. 3.4.5. Leg. 4. Exp. 9. 12 y 16.

La intensa participación en la sociedad de los sectores ajenos al mundo artesanal fue indudablemente impulsada por los excelentes resultados obtenidos en sus primeros años de actividad. Este aspecto se ha logrado conocer gracias a la información contenida en el "Libro de deliberaciones de la compañia» y al análisis de diversas certificaciones realizadas por su secretario ${ }^{12}$. Sus resultados se han plasmado en el cuadro n. ${ }^{\circ}$. El primer aspecto que se deriva de su análisis es el crecimiento ininterrumpido de la cifra total de beneficios que se produjo hasta el ejercicio $1778-79$, en el que se alcanzaron las 11.960 libras. Se trata de una cifra realmente elevada, que se sitúa en la línea de la alcanzada por las compañias comerciales más importantes cuyos resultados se han logra-

12 A.C.A.M.S.V. Sig. 2.3.1. Libro 21. Las referencias a los resultados de los diversos ejercicios se encuentran en las juntas celebradas en las siguientes fechas: 6.11-1774; 8-11.1775; 9.11.1776; 26-11-1777; 9-12.1778; 15-12-1779; y 31-1-1781. Los resultados de los ejercicios 1781-82 y 1782 . 83 se conocen gracias a sendas certificaciones emitidas por el secretario de la compañia en 1784 . Ver A.C.A.M.S.V. Sig. 3.4.5. Leg. 4 Exp. nums. 9 y 12 . Los ejercicios se extendian entre el 1 de noviembre y el 31 de octubre de cada año. Las cifras de cada ejercicio corresponden a beneficios liquidos, deducidas ya las cantidades destinadas a remunerar a los cargos directivos. La proporcion que representaban con respecto al capital es la calculada por la propia compañia, con excepción del ejercicio 1773-74, en el que, al no aludirse a este extremo, se ha calculado tomando como referencia el capital suscrito hasta el 31-10-1774. 
do conocer y que supera los ingresos anuales de la mayor parte de las casas nobiliarias estudiadas ${ }^{13}$. Sin embargo, porcentualmente, las tasas de beneficios más elevadas se lograron en los tres primeros ejercicios, cuando oscilaron entre el 7 y el 10,5 \% $\%$. Fue, seguramente, la obtención de una rentabilidad tan atractiva lo que provocó la auténtica avalancha de suscripción de acciones que se produjo en el ejercicio 1776.77, en el que se llegó prácticamente a duplicar el capital de la compañia. Al producirse un incremento tan rápido del capital, la tasa de beneficios comenzo a flexionar a la baja, hasta situarse en el $4,39 \%$ en el ejercicio 1777-78. Y es que la compañia comenzaba a tener un exceso de liquidez para el volumen de negocios que realizaba. Asi lo expreso el propio director en la junta celebrada el 7 de noviembre de 1778, al afirmar que, tras la compra de seda que se efectuaba en cada ejercicio y hasta la cosecha siguiente, «... se juntava y detenia mucho dinero en el arca, y le parecia sería muy del caso el que se pensase en ver cómo dar giro a este dinero...» ${ }^{14}$. La decisión que se adoptó fue la de introducirse en el negocio del giro de letras de cambio, y de proceder, además, a la devolución de algunos capitales que la compañía tenía en depósito. Todo ello, junto con el incremento del volumen del tráfico, pudo favorecer la elevación de la tasa de beneficios hasta el $6,93 \%$ en el ejercicio 1778-79. Sin embargo, cuando la compañia parecia estar consolidándose, fue duramente golpeada por la crisis comercial derivada de la intervención de España en la guerra de independencia de las Trece Colonias americanas. La paralización del tráfico que provocó este conflicto no fue acompañada por una paralela reducción de la actividad de la fábrica, como veremos posteriormente, lo que determinó que se acumulasen las existencias de tejidos invendidos. Asi lo expresaba la propia dirección de la compañia, que en su junta de 7 de febrero de 1781 constataba la practica inexistencia de dinero en efectivo «... por estar todo invertido en géneros de texidos de seda fabricados y sedas torcidas...» 15. Como consecuencia de esta situación, en el ejercicio de 1779-80 se experimentaron unas perdidas de 3.813 libras, lo que, según la compañia, representaba el $2,14 \%$ del capital social. Y, por primera vez desde su creación, no se distribuyó ningún dividendo a los accionistas. El resultado del ejercicio 1780-81 fue también negativo, aunque la dimensión exacta de las pérdidas es algo controvertida. En la sesión celebrada por la Junta del Consejo el 27 de diciembre de 1781 se indica que las pérdidas ascendieron a 964 libras. Sin embargo, en enero de 1784 el secretario de la junta de apoderados de la compa-

"Sobre los beneficios obtenidos por diversas companias comerciales valencianas ver Franch (1989 a), pp. 230-231. Sobre los ingresos de la nobleza valenciana, ver Catala (1995), pp. 16.

is A.C.A.M.S.V. Sig. 2.3.1. Libro 21. Deliberación de la Junta de Dirección de 7.11.1778.

15 A.C.A.M.S.V. Sig. 2.3.1. Libro 21. Deliberación de la Junta de Consejo de 7-2-1781. 
ñia extendió una certificación según la cual en aquel ejercicio la compañia re. sultó «alcanzada» en 9.320 libras, representando la pérdida el 5,5\% del capital social ${ }^{16}$. En todo caso, fue esta última cantidad la que se tomó como base para calcular los beneficios del ejercicio 1781-82, en el que el «alcance» se redujo a 7.120 libras, lo que significaba que aquéllos habian ascendido a 2.200 libras, el $1,37 \%$ del capital social. En este ejercicio se habria comenzado a superar la crisis, aunque sus efectos aminoraron considerablemente el saldo positivo obtenido, puesto que, para dar salida a las mercancias existentes en los almacenes, se tuvieron que vender a un precio inferior al de coste. De todas formas, teniendo en cuenta que los accionistas llevaban ya «... dos años que no perciven utilidad alguna...», se acordo mantener el «alcance» (incrementándolo incluso ligeramente) y distribuir un dividendo del $2 \%$. La recuperación se consolidó en el ejercicio 1782-83, en el que se obtuvieron unos beneficios de 9.722 libras, el $6,33 \%$ del capital. No obstante, a los accionistas sólo se les distribuyó un dividendo del $3 \%$ con el fin de reducir el «alcance» acumulado en los años anteriores. Y la tendencia positiva debió de continuar en el ejercicio 1783-84, del que sólo conocemos que el dividendo distribuido fue del $5 \%{ }^{17}$. Sin embargo, a pesar de que la situación financiera de la compañia iba mejorando, ésta no logró salir indemne de las dificultades atravesadas entre 1779 y 1781, ya que las graves pérdidas experimentadas provocaron el afloramiento de graves disensiones entre los accionistas que acabaron conduciendo a la disolución de la sociedad en 1785 .

El motivo fundamental que provocó los enfrentamientos fue la decisión de mantener la actividad manufacturera de la compañia a pesar de la paralización del tráfico que se produjo durante la guerra. La opción habia sido ruinosa en términos estrictamente económicos, al provocar graves pérdidas, pero resultaba coherente con el objetivo de fomentar la actividad de las fábricas que la compañia tenía para los sectores artesanales. No obstante, la mayoria de los accionistas no compartian este último criterio, y contemplaron la situación como el fruto de una mala gestión que exigía el cambio no sólo del equipo de dirección, sino también de la disposición que reservaba su ejercicio a los maestros del arte mayor de la seda. Este malestar coincidió con el cumplimiento en no-

16 A.C.A.M.S.V. Sig. 3.4.5. Leg. 4 Exp. num. 9. Probablemente, para calcular exactamente la cifra de perdidas del ejercicio 1780.81 habria que restar a esta cantidad las 3.813 libras perdidas en el ejercicio anterior. Sin embargo, esto parece que no se ha tenido en cuenta al situar la tasa de perdidas en el $5,5 \%$, puesto que, segun la misma certificación, el capital social de la compañia en 1782 era de 159.600 libras.

17 Los resultados del ejercicio 1782.83 pueden verse en A.C.A.M.S.V. Sig. 3.4.5. Leg. 4. Exp. num. 12. En el expediente num. 16 se halla la referencia al dividendo del $5 \%$ distribuido en el ejercicio 1783-84. 
viembre de 1781 del segundo cuatrienio de actividad de la compañia, lo que, según los estatutos, exigia la convocatoria de una Junta General de Accionistas para examinar las cuentas y proceder a la renovación parcial de los cargos directivos. Fue en esta Junta, que se convocó finalmente el 2 de enero de 1782, donde el mayoritario sector no artesanal del accionariado impuso sus criterios, procediéndose al nombramiento de una «Junta de Apoderados» para asumir el gobierno de la compañia que vulneraba claramente lo dispuesto en sus estatutos. Ya que en ella se limitaba a dos representantes la presencia de los maestros del colegio del arte mayor de la seda, procediendo los seis miembros restantes de los otros sectores sociales del accionariado ${ }^{18}$. La nueva Junta fue distanciándose progresivamente de la corporación artesanal que habia promovido la sociedad, lo que provocó una firme reacción defensiva por parte de aquélla, materializada en su oposición a la modificación de los estatutos de la compañia. Pero, al no lograr reconducir la situación, el colegio comenzó a considerar que la compañia se estaba apartando de sus objetivos originales y que, por tanto, no merecia la pena mantener el proyecto. Esta decision ya se adoptó en noviembre de 1784 , pero se planteó abiertamente en febrero de 1785 al solicitar el colegio, acogiéndose a lo dispuesto en los estatutos de la compañia, el reintegro de su capital invertido en acciones al cumplirse, en noviembre de 1785, los 12 años de funcionamiento de la sociedad. La Junta de Apoderados criticó acidamente esta decisión, considerando ilogico que el principal promotor de la compañia se separase de ella y atribuyendo las graves pérdidas sufridas a la desastrosa gestión de los artesanos sederos. Pero no vio otra alternativa para resolver la cuestion más que la convocatoria de una Junta General de Accionistas en la que se deliberase el futuro de la sociedad. Ésta se celebró finalmente el 3 de noviembre de 1785, y en ella se impuso la propuesta de proceder a la disolución de la sociedad por 113 votos frente a los 41 que se inclinaron por su continuidad. Remitida la decision a la Junta General de Comercio, fue aceptada por ésta en la orden de 21 de julio de $1786^{19}$.

ix La composición de la Junta de $A$ poderados se ha logrado conocer gracias a las certificacio. nes extendidas por su secretario en los años 1784 y 1785. A.C.A.M.S.V. Sig. 3.4.5. Leg. + Exp. 9.16. Los dos representantes del colegio del arte mayor de la seda cran Félix Piñó, que asumia la función de director de la compañia, y el propio mayoral del colegio. Por su parte. las seis perso. nas que no pertenecian al colegio eran: Luis Bertet, preshitero; Cristobal Tarazona, abogado; Gaspar Ferrer, con tratamiento de "Don" y que en alguna ocasion es identificado como caballe. ro de la Orden de San Juan de Jerusalén; Silvestre Salelles, sin tratamiento en el momento de adquirir las acciones; Arnaldo Veys, sin tratamiento en el momento de adquirir las acciones, y Pas. cual Peris, maestro tintorero.

$1+$ El proceso que condujo a la disolución de la sociedad puede verse en A.C.A.M.S.V. Sig. 3.4.5. Leg. 2 Exp. num. 6; y Leg. 5. Exp. num. 13-15. La propuesta del colegio del arte mayor de la seda para solicitar la devolucion del capital invertido en la compania fue lanzada por su mayo- 
Por tanto, la crisis de 1779-81 agudizó las contradicciones de una compañia que habia logrado consolidarse gracias a la superación de su inicial carácter artesanal, pero que no habia adaptado los órganos directivos a su nueva naturaleza. De ahi que cuando la mayoria de los accionistas trataron de forzar esta adaptación tras haber sufrido graves pérdidas como consecuencia de la «peculiar» gestión de los artesanos, el colegio del arte mayor de la seda reaccionase en defensa de sus prerrogativas y adoptase una actitud claramente obstruccionista. De todas formas, y a pesar de su fracaso, el analisis de sus negocios nos permite profundizar en el conocimiento de la sederia valenciana dieciochesca.

\section{LA ACTIVIDAD MANUFACTURERA DE LA COMPAÑÍA}

Como continuadora del posito que habia creado el colegio del arte mayor de la seda en 1757, la Compañia de Nuestra Señora de los Desamparados siguio desempeñando una importante actividad en la adquisición de seda en rama y en su ulterior semielaboración con el objetivo de ofertarla con mayor regularidad a los fabricantes. Esta faceta sólo se ha logrado reconstruir de forma algo incompleta. En el «Libro diario de piezas trabajadas por cuenta de la compañia» figuran, anotadas con cierto desorden, las compras de seda efectuadas entre 1775 y $1781^{20}$, y sus datos se han plasmado en el cuadro n. ${ }^{\circ} 3$. Como puede apreciarse, salvo en 1775 , en que los datos son incompletos, y en 1780 y 1781 , que se vieron afectados por la crisis provocada por la guerra, las adquisiciones siempre superaron las 14.000 libras de 12 onzas, llegando a la cota máxima de 18.307 libras en 1777 . Se trata de una cifra que doblaba en exceso la manejada por el pósito del colegio en los años de mayor actividad ${ }^{21}$ y que requeria una inversión de alrededor de 60.000 libras valencianas. Las operaciones se centraban básicamente en la adquisición de seda de tipo hilan-

ral el 26-11-1784 y aceptada por la corporacion el 11.2-1785. Ver las juntas de ambas fechas en el aLibro de deliberaciones del colegiom. Sig. 2.5.2. Libro 5.

2" A.C.A.M.S.V. Sig. 2.3.2. I.ibro 1. Ver fols. $20+43$ y 170.183. Cabe advertir que las operaciones, que se han plasmado en el cuadro num. 3, estan agrupadas por cosechas agricolas, pues las adquisiciones solian realizarse en los meses inmediatamente posteriores a estas con el fin de aprovechar la elevada of erta y conseguir buenos precios. Fl año 1775 es el más problematico, ya que en el libro sólo se anotaron las sedas existentes en el balance de 30 de octubre de 1775 (4.482 libras de 12 onzas) y las adquisiciones que se realizaron a partir de entonces.

$"$ En sus momentos de mayor actividad, el posito del colegio llego a adquirir y toreer alrededor de 7.000 libras de 12 onzas de seda. Las cuentas de su administración pueden verse en A.C.A.M.S.V. Sig. 3.6.4. Leg. 10. 
dera, que era la de mayor calidad y precio, mientras que las de tipo hilandero y trama eran más irregulares.

\section{CUADRO 3}

Compras de seda efectuadas por la Compañia de Nuestra Señora de los Desamparados entre 1775 y 1781 (peso expresado en libras de 12 onzas y valor en libras valencianas.

\section{Datos redondeados)}

\begin{tabular}{|c|c|c|c|c|c|c|c|c|}
\hline \multirow[b]{2}{*}{ Coserba } & \multicolumn{2}{|c|}{ HHLANDLRA } & \multicolumn{2}{|c|}{ HWADERO } & \multicolumn{2}{|c|}{ IR.MAA } & \multicolumn{2}{|c|}{ Tolat } \\
\hline & Peso & Valor & Peso & Valor & Peso & Valor & Peso & Valor \\
\hline 1775 & 7.504 & 30.943 & 1.010 & +.101 & 202 & 718 & 8.716 & 35.762 \\
\hline 1776 & 8.400 & 34.277 & - & & 5.719 & 21.183 & 14.119 & 55.460 \\
\hline 1777 & 12.455 & 47,606 & 3.191 & 10.974 & 2.661 & 9.872 & 18.307 & 68.452 \\
\hline 1778 & 14.189 & 57.381 & $\ldots$ & - & - & - & 14.189 & 57.381 \\
\hline 1779 & 1.035 & 3.977 & 760 & 2.919 & 13.990 & 50.924 & 15.785 & 57.820 \\
\hline 1780 & 4.598 & 16.269 & 732 & 2.309 & 277 & 841 & 5.607 & 19.419 \\
\hline 1781 & 6.695 & 25.251 & 195 & 676 & 3.772 & 12.504 & 10.662 & 38.431 \\
\hline
\end{tabular}

F(L)Tl: A.C.A.M.S.V. Sig. 2.3.2. Libro 1.

Tras su adquisicion, la compañia procedia a efectuar el devanado y torcido de la materia prima, operaciones para las que se contrataban los servicios de diversos maestros torcedores. En los libros de control que se llevaban al efecto se citan una veintena larga de ellos, aunque parece que sólo se llegó a dar trabajo simultaneo a unos 9 torcedores ${ }^{22}$. Realmente, las relaciones con los torcedores eran bastante conflictivas, ya que éstos se hallaban reivindicando en esos momentos la elevación del precio que se les abonaba por el torcido y la segregación del control de la operación del devanado ${ }^{23}$. Esta última cuestión no fue planteada abiertamente a la compania, centrándose, en cambio, los problemas en la remuneración del trabajo, que aún era idéntica a la abonada por el posito del colegio en la decada de 1760 . El fuerte tirón alcista que habian experimentado desde entonces los precios comenzó a arrastrar también a los salarios ${ }^{24}$, y la presión que en este sentido comenzaron a ejercer los torcedores

22 Los libros de control de los torcedores, en A.C.A.M.S.V. Sig. 2.3.2. Libros 11 y 12. La referencia a que sólo llegaron a trabajar simultáneamente para la compañia 9 torcedores se realizo en la Junta del Consejo de la compaña celebrada el 30-4.1779. A.C.A.M.S.V. Sig. 2.3.1. Libro 21.

23 Diez (1992), p. 49.

24 Ver la evolución comparada de ambas variables en Valencia en Palop (1977), pp. 26-27. Por su parte, el precio que hasta mediados de la decada de 1770 se venia pagando a los torcedores cra el siguiente: 10 sueldos por libra en la seda hilandera, 9 sueldos por libra en la seda hilan- 
logró alcanzar sus objetivos gracias a la quiebra del frente común que habian realizado los fabricantes por parte de la Real Fábrica de los Cinco Gremios. Asi se indica, al menos, en la Junta del Consejo de la compañia del 26-4-1777, en la que se atribuye la falta de torcedores dispuestos a trabajar en las condiciones anteriores a la subida de 6 dineros por libra y un $0,5 \%$ en los «desperdicios» que habia efectuado aquélla, lo que obligaba a los demás fabricantes a ofrecer la misma remuneración. El forcejeo continuó posteriormente, y a mediados de 1778 se volvió a incrementar la remuneración en otros 6 dineros por libra. Finalmente, en agosto de 1779 se produjo un aumento adicional de 1 sueldo por libra y un $0,5 \%$ en los «desperdicios», manteniéndose ya inmóviles estas condiciones hasta la disolución de la compañia en 1785.

A pesar de las tensas relaciones que se mantenian con los torcedores la compañia no realizó un serio esfuerzo para controlar directamente esta actividad, adoptando una actitud idéntica a la de los restantes fabricantes valencianos. Las razones de este comportamiento son difíciles de dilucidar, pero lo cierto es que con ello se contribuia a mantener las deficiencias que afectaban a la hilatura y el torcido de la seda valenciana. Realmente, las pocas iniciativas que se adoptaron en este sentido se enmarcaron en la campaña en favor de la difusión del método de Vaucanson que culminó con el establecimiento de la fäbrica de Vinalesa. Pero, al igual que ocurrio en este caso, la elevada inversión que requería la creación de una manufactura de esta indole constituyó un grave inconveniente, que se acentuó al coincidir la mayor parte de los esfuerzos con la coyuntura critica de finales de la década de $1770^{25}$.

La compañia tambien se vio impulsada a favorecer la difusión del método de Vaucanson, al exigirselo la Junta General de Comercio en una orden emitida el 16 de marzo de 1779. Con esta finalidad, se procedió al arrendamiento del «huerto de Datos», en el que se instalaron 14 tornos para la hilatura de seda según el nuevo sistema. Pero, inmediatamente, comenzaron a surgir las complicaciones que se derivaban de esta innovación: al tener que adquirirse capullos de seda, los intermediarios que se encargaban de efectuar las compras de materia prima por cuenta de la compañia exigieron una comisión del $3 \%$, en lugar del $1 \%$ percibido anteriormente; se contrató a diversos expertos para el tratamiento de los capullos de seda y el control del trabajo de las hilanderas, pero el desconcierto que todo ello creó obligó a la Junta de Dirección de la

\footnotetext{
dero y 4 sueldos por libra en la seda trama. Además. se descontaba un $4 \%_{0}$ de la cantidad de seda hilandera o hilandero entregada al torcedor en atencion a los edesperdicios» que se pudieran derivar de la operación, proporción que se reducia al 3 o en el caso de la seda trama.

"Sobre los problemas de la hilatura y el torcido tradicional y las ventajas del metodo de Vaucanson, ver Martinez Santos (1981), pp. 183-218.
} 
compañia a asumir directamente (por turnos semanales) la supervisión del proceso; y la toma de conciencia de que los torcedores podian contrarrestar la calidad lograda por la hilatura con el nuevo sistema impulsó a la compañia a solicitar permiso al intendente para poder disponer de tornos propios. El nuevo método había forzado, pues, a la compañia a tratar de integrar en su negocio manufacturero el proceso de semielaboración de la materia prima. De hecho, tras el auto favorable del intendente del 20 de septiembre de 1779 , se comenzaron a construir diversos tornos y, sobre todo, se llegó a plantear el proyecto de creación de una manufactura en Godella en la que se instalarian 15 tornos accionados por la tracción hidráulica proporcionada por la acequia de Moncada. Sin embargo, el coste de 12.000 libras valencianas en que se estimó el proyecto se consideró excesivo, y más teniendo en cuenta la coyuntura de crisis comercial que se estaba experimentando. De ahi que se dispusiese instalar los 4 tornos que se habian construido en la Casa de la Misericordia, aprovechando la contrata que se habia hecho con ésta para ocupar a sus mujeres en el devanado de la seda. Sin embargo, el coste del devanado y el torcido en estos tornos acabó resultando superior al abonado habitualmente a los torcedores (salia a 13 sueldos y 2 dineros por libra, frente a los 12 sueldos que se pagaban a aquéllos). De ahi que el 29 de enero de 1782 la compañia acordase ceder su explotación a un torcedor mediante la firma de una contrata. Por tanto, la complejidad del nuevo método de hilatura y torcido, que llevaba inevitablemente hacia la constitución de una manufactura centralizada, y su elevado coste, se convirtieron en graves obstáculos que dificultaron su difusión. Y más teniendo en cuenta que la coyuntura en la que se concentraron las iniciativas (en plena crisis de $1779-81$ ) no era demasiado propicia. El hecho de que la compañía acabara abandonando los nuevos métodos y volviendo al sistema tradicional puede ayudarnos a comprender las escasas iniciativas adoptadas en esta linea por la burguesia sedera. Tal vez la sistemática importación de materia prima extranjera que se produjo a partir de mediados de la década de $1780^{26}$, al suministrar una seda de excelente calidad, acentuase el desinterés por la adopción de un negocio que parecia tan complejo y costoso.

Tras la semielaboración de la materia prima, la compañia la ofrecía a los fabricantes con la finalidad de que éstos dispusiesen de una fuente de abastecimiento más regular. Su precio de venta era revisado periódicamente por la Junta de Dirección, tomando como referencia básica la evolución de los precios de la seda negociada en el «contraste». De ahi que su tendencia siguiera el ritmo estacional marcado por el carácter agricola de la producción, aunque en

26. Franch (1989 b), pp. 77.80 . 
algún caso se atribuyera también a la presión de la demanda del mercado colonial la tendencia alcista que estaban experimentando en ese momento los pre$\operatorname{cios}^{27}$. De todas formas, la compañia siempre estipulaba unos precios ligeramente inferiores a los demandados en el "contraste» por los torcedores de seda ${ }^{28}$, cumpliendo con ello su objetivo de tratar de hacerlos flexionar hacia la baja. Realmente, todo parece indicar que el beneficio que obtenia en su labor de intermediación era bastante ajustado, procediendo básicamente de la adquisición de la seda a unos precios ventajosos en los meses inmediatamente posteriores a la cosecha. En muy contadas ocasiones se nos indica expresamente la diferencia entre el coste de la seda ya semielaborada y su precio de venta, y, en estos casos, el margen de beneficio oscila entre el $1,92 \%$ y el $7,69 \%$. Una impresión similar se desprende de la comparación entre los precios medios de adquisición de la seda y los precios medios de venta, deduciendo los costes del devanado y el torcido ${ }^{29}$. En todo caso, no cabe duda que la compañia desplegaba una actividad que resultaba muy satisfactoria para los pequeños fabricantes.

Pero aparte de proseguir, con un volumen acrecentado, la labor desarrollada por el antiguo pósito de seda, la compañia también incluyó entre sus negocios la elaboración de tejidos de seda, a pesar de la resistencia que habia planteado en contra de esta posibilidad la burguesia sedera. Tal vez por ello, su actividad en este ámbito se emprendió muy lentamente, adoptándose la decision a mediados de 1775 , cuando la compañia ya llevaba casi dos años en funcionamiento. También puede ser significativo que la iniciativa partiese de diversos artesanos modestos, que pidieron a la dirección que «... se les diese algún consuelo en disponer y llevar algunos telares....». Ante esta solicitud, la compañia acordó el 28 de junio de 1775 dar trabajo a entre 10 y 12 telares. Pero, para la dirección, esta actividad debia de tener exclusivamente un carác-

"Asi, en las Juntas de Dirección celebradas el 5-6.1778 y el 16-11-1781 se afirmó explicitamente que la llegada de la flota de Indias a Cadiz era el motivo fundamental que impulsaba al al. za los precios de la seda. A.C.A.M.S.V. Sig. 2.3.1. Libro 21. Sobre el ritmo estacional de los precios y de la comercialización de la seda en el "contraste», ver Franch (1990).

2k Asi, por ejemplo, en la Junta de Direccion del 9-6.1779 se tuvo en cuenta que los torcedores vendian la seda a entre 53 y 54 reales valencianos la libra para fijar los precios de la seda hilandera torcida entre 51 y 53 reales, en función de su mayor o menor finura (la delgada, a 53; la mediana, a 52, y la gorda, a 511. A.C.A.M.S.V. Sig. 2.3.1. Libro 21.

${ }^{24}$ Las ocasiones en que se indica la diferencia entre el coste de la materia prima ya semiela. borada y el precio de venta se encuentran en las juntas celebradas por la compañia el 5-12-1775. el 7.8.1778 y el 4-11-1778. En el mismo libro de deliberaciones de la compañia se hallan todos los acuerdos de revisión periódica de los precios de venta de la seda torcida, y sus precios se pueden comparar con los de adquisicion de la materia prima, teniendo en cuenta que el coste del devanado y el torcido comenzó teniendo una incidencia de 7 reales valencianos por libra y acabo ascendiendo a 9 reales. 
ter secundario, y en diversas ocasiones se explicitó que sólo se podría elaborar la tercera parte de las sedas torcidas existentes, destinándose las dos terceras partes restantes al objetivo prioritario de abastecer a las fábricas ${ }^{30}$. Sin embargo, si bien inicialmente parece que se respetó dicha limitación, el espectacular incremento del capital que experimentó ulteriormente la compania y su exceso de liquidez pudieron acentuar su intervención en la fábrica. Asi se desprende del análisis de los libros diarios de piezas trabajadas por cuenta de la compañia "1, cuyos datos se han plasmado en el cuadro n." 4. Como puede apreciarse, partiendo de unas cifras bastante bajas, en los años 1778 y 1779 ya se alcanzó una producción considerable, que rondaba las 40.000 varas valencianas. El peso de alrededor de 7.500 libras de 12 onzas de seda que ello representaba suponia una cuota muy próxima al $50 \%$ de la seda en bruto comprada por la compañia en estos años, lo que evidencia que ésta estaba superando sus propias limitaciones y se estaba convirtiendo en una auténtica empresa sedera. Sin embargo, fue su vinculación artesanal lo que determinó que su reacción ante la crisis derivada de la guerra contra Inglaterra no se ajustara a unos criterios estrictamente empresariales. Ya en enero de 1780 la dirección acordo la paralización de la actividad de los 26 telares que fabricaban tejidos para su venta en Cádiz ante el aviso de que se habia aplazado la sa. lida de las expediciones hacia América. Pero esta decisión se vio contrarrestada por la presión del artesanado para que la compañia contribuyera a combatir la creciente desocupación de las fábricas, $y$ más teniendo en cuenta que el colegio cedió en su favor la limosna de 10.000 libras que el arzobispo de Valencia le habia entregado con la misma finalidad. El resultado de todo ello fue que en el año 1780 se alcanzo la cifra más elevada de producción de tejidos de seda de la historia de la compañia ${ }^{32}$. De ahi las graves pérdidas que se experimentaron en los ejercicios de 1780 y 1781 , en los que se produjo una

"A.C.A.M.S.V. Sig. 2.3.1. L.ibro 21. Ver los acuerdos de 18-2-1776; 29-7-1776; y 18-5-1779.

"A.C.A.M.S.V. Sig. 2.3.2. Libros 1 (que comprende los tejidos tabricados entre 1774 y 17831, 2 tque recoge los tejidos fabricados con la inversion de las 10.000 libras entregadas por el arzo. bispo de Valencia para paliar la paralizacion de las fabricas durante la guerra contra Inglaterra) y 6 tque contiene los tejidos fabricados entre 1783 y 1785 I. Sobre sus resultados, que se han plas. mado en el cuadro num. 4, cabe advertir que en las fuentes no se especifica la extension de 303 cortes de saya, que se hallan, no obstante, perfectamente valorados.

'Z En 1780 la compañia claboró por su propia iniciativa $34.601,5$ varas, a las que se añadie ron las 12.479,5 varas fabricadas a partir de la limosna otorgada por el arzobispo. Cabe scnalar que este dinero se destinó exclusivamente al ahono de las herramientas y los salarios empleados en la semiclaboracion de la seda, siendo su adquisicion previa y elaboracion ulterior por cuenta de la compaña. De ahi que, segun las cuentas realizadas en 1784 , solo se invirtiesen realmente de los fondos procedentes de la limosna 3.402 libras, devolviendose al arzobispo las 6.598 libras restantes entre 1783 y 1784 . Las cuentas elaboradas en este sentido se hallan en A.C.A.M.S.V. Sig. 3.4.2. Leg. 18. 
brusca reducción de la demanda. La acumulación de existencias acabó reduciendo la actividad manufacturera, que llegó a sus niveles más bajos en 1782. Incluso la recuperación experimentada en los ejercicios posteriores fue muy timida, cortandose de nuevo bruscamente en 1785 como consecuencia del inicio del proceso de disolución de la sociedad. Por tanto, fue precisamente la excesiva orientación manufacturera de la compañia, mantenida con fines asistenciales durante la crisis derivada de la guerra contra Inglaterra, lo que marcó profundamente su evolucion, contribuyendo decisivamente a su fracaso final.

\section{CUADRO 4}

Producción anual de tejidos de seda de la Compañia de Nuestra Señora de los Desamparados (extensión expresada en varas, peso en libras de 12 onzas y valor en libras valencianas)

\begin{tabular}{|c|c|c|c|}
\hline Año & Extenssion & Peso & Valor \\
\hline 1774. & 87,25 & 37,65 & 349,38 \\
\hline 1775 & 2.343 .50 & 525,25 & $4.755,40$ \\
\hline$\ldots \ldots \ldots \ldots$ & $8.721,50$ & $1.931,16$ & $19.024,68$ \\
\hline ............. & $21.519,16$ & $4.425,47$ & $40.654,19$ \\
\hline 1778 & $38.915,25$ & $7.577,75$ & $64.998,38$ \\
\hline 1779 & $38.115,25$ & $7.241,92$ & $66.422,55$ \\
\hline 1780 & $47.081,00$ & $8.646,65$ & $74.751,73$ \\
\hline 1781 & $16.669,50$ & $3.543,48$ & $29.322,05$ \\
\hline 1782 & $4.886,50$ & $1.060,56$ & $8.248,45$ \\
\hline 1783 & $16.765,00$ & $3.236,04$ & $31.142,26$ \\
\hline 1784 & $12.559,25$ & $1.829,17$ & $20.479,94$ \\
\hline 1785. & $2.788,50$ & 357.73 & $4.477,38$ \\
\hline Total. ..... & $210.451,66$ & $40.412,82$ & $364.626,39$ \\
\hline
\end{tabular}

FU.NTE: I.ibros diarios de piezas que se trabajan por cuenta de la compañia. A.C.A.M.S.V. Sig. 2.3.2. Libros 1,2 y 6 .

Los tipos de tejidos elaborados por la compañia eran muy diversos. En los libros diarios de fabrica se han podido distinguir hasta 57 variedades diferentes, aunque sólo 19 de ellas alcanzaron una presencia significativa. Considerando el valor de la producción, el terciopelo es el tejido más importante, al representar el $14,89 \%$ del total, aunque esta proporción se reduce a la mitad si se tiene en cuenta la extensión del tejido. Esta divergencia se derivaba de la solidez y elevado precio del producto, ya que cada vara tenía un peso medio 
de 4,5 onzas de seda y un coste de producción de 3,58 libras valencianas. Situación inversa se daba en el caso del tafetán, que era el tejido del que se produjo una extensión mayor (el $12,05 \%$ ), pero cuyo valor sólo representaba el $8,34 \%$. Se trataba de un tejido más barato y ligero, ya que cada vara tenia un peso medio de 1,5 onzas de seda y un coste de producción de 1,20 libras valencianas. De entre los restantes tipos de tejidos, sólo el fondo (que supuso el $2,97 \%$ de la extensión y el $6,25 \%$ del valorl presentaba unas caracteristicas similares a las del terciopelo. Los restantes eran tejidos de un peso y valor intermedios que se diferenciaban básicamente por el tipo de ligamento o la forma de confección. Destacaban entre ellos el damasco $(10,38 \%$ de la extensión y $10,29 \%$ del valor), el raso $(9,94 \%$ y $8,45 \%$, respectivamente), la musulmana $(7,88 \%$ y $7,14 \%)$, etc.

La elaboración de los tejidos tenia lugar a través de la utilización del «putting-out system», pero dentro del marco gremial existente en la ciudad de Valencia. El número de telares controlados por la compañia fue muy diverso. En un principio se tomó el acuerdo de dar trabajo sólo a entre 10 y 12, pero la cifra se fue incrementando progresivamente con posterioridad. En los libros de control que se llevaban al efecto ${ }^{33}$ se puede apreciar que su numero solia rondar en torno a los 50 , aunque no todos ellos trabajaban con la misma intensidad. Aparte de que el artesano pudiera dedicar parte de su actividad a trabajar por su propia cuenta o para otro empresario sedero, su distinto nivel productivo dependia también del grado de complejidad del producto que elaboraba ${ }^{34}$. En todo caso, este factor era el que determinaba la remuneración del trabajo por parte de la compañia. Según los libros de control de los fabricantes, el abanico salarial era muy amplio, situándose en los 24 sueldos por vara en el caso del fondo; los 13 sueldos por vara, en el terciopelo; los 8 sueldos por vara, para el raso, el tafetán y el brocado; los 6 sueldos por vara, para el damasco, la albanesa y el rasillo, etc. En todos los casos, además, al fabricante se le abonaban por desperdicios o «juntas» un cuarto de onza por cada libra de seda consumida. Y el sistema de pago solía consistir en el abono anticipado de una cantidad semanal determinada (que ascendia habitualmente a 3 libras), procediéndose a la liquidación a la entrega de la pieza confeccionada.

Sin embargo, la forma de operar de la compañia parece que cambió tras la grave crisis de 1780.81 y el subsiguiente desplazamiento del artesanado en la

"A.C.A.M.S.V. Sig. 2.3.1. Libros 7 a 12.

it Asi, Lapayese afirmaba en su tratado que un tejedor solía confeccionar diariamente 4 varas de damasco, mientras que el colegio del arte mayor de la seda indicaba en 1811 , en una encuesta de indole fiscal, que un telar de raso solia confeccionar tres varas diarias, y uno de terciopelo sólo una vara diaria. Ver Lapayese (1779), pp. 10. Los calculos del colegio del arte mayor de la seda en A.C.A.M.S.V. Sig. 2.5.4. Libro 1. Fol. 18.19. 
dirección. Aparte de que la cifra de tejidos producidos se redujo considerablemente, todo parece indicar que los que se manejaban entonces no eran elaborados por cuenta de la compañia. Asi se desprende del hecho de que el libro de control de los fabricantes finalice en 1782 y de que en el libro diario de piezas fabricadas que se inició a partir de 1783 se especificase que las telas habian sido «... mercadas a diferentes particulares...». La crisis derivada de la guerra contra Inglaterra nos aparece, de nuevo, como un factor trascendental que marcó profundamente la evolución de la compañia.

\section{LA COMERCIALIZACIÓN DE LOS TEJIDOS DE SEDA}

Los tejidos elaborados por la compañía tenían dos vías básicas de comercialización: el almacén que se cré para su venta al por mayor o al por menor en la propia ciudad de Valencia; y la ciudad de Cádiz, en donde los corresponsales procedian a su venta a los cargadores de Indias. En los libros diarios de fábrica de la compañia son éstos los dos destinos básicos que se asignan a cada una de las piezas elaboradas. Parece, incluso, que existio un cierto equilibrio entre ambos, ya que los tejidos en los que se anotó expresamente su remisión a Cádiz representaron el $33,43 \%$ de la extensión producida entre 1774 y 1785 , y el $41,35 \%$ de su valor. Pero como a ellos se unieron otros tejidos destinados inicialmente al almacén, si se analizan las cuentas de venta de los corresponsales gaditanos, la proporción se eleva hasta el $37,25 \%$ de la extension y el $56,73 \%$ del valor, aunque en este último caso habria que descontar los beneficios derivados de la comercialización ${ }^{35}$. Por tanto, la actividad de la Compañia de Nuestra Señora de los Desamparados confirma claramente la in. tensa orientación hacia el mundo colonial que adquirio la sederia valenciana dieciochesca, hasta el punto de constituir su principal mercado de destino ${ }^{36}$. De ahi que será este ámbito el que centrara especialmente nuestra atención. Por lo demás, la actividad desplegada en los almacenes de Valencia tampoco generó una información de especial interés. Estuvieron regidos por tres encargados sucesivos, quienes percibian en remuneración de su trabajo el $2 \% \mathrm{del}$ valor de las ventas $1,5 \%$ como comisión y $0,5 \%$ en compensación por las mermas producidas en el «vareo»). Los libros de cargo y descargo en que se anotaron sus operaciones se han conservado, pero su analisis requeriria un esfuerzo excesivo que seguramente no se vería compensado por la obtención de

"Los libros diarios de fabrica en A.C.A.M.S.V. Sig. 2.3.2. Libros 1, 2 y 6. Las cuentas de venta de los corresponsales gaditanos se hallan en el mismo archivo. Sig. 3.4.3. Legs. 88-98.

36 Asi se deduce del analisis de los negocios de diversas dinastias sederas. Ver Franch (1989 a). 
unos resultados de cierta entidad. En cambio, los libros de facturas, las cuen. tas de venta y la correspondencia que generó la comercialización de los tejidos hacia Cadiz ${ }^{37}$ nos permiten reconstruir con cierto detalle los mecanismos en los que se basaba el negocio, posibilitando incluso en muchos casos el cálculo de los márgenes de beneficio que se derivaban de la actividad.

Los corresponsales con los que trabajó la compañia en Cádiz fueron tres. En un principio, las remesas se dirigieron en exclusiva a la consignación de Diego Lostau, que era el agente más importante que utilizaba el comercio valenciano en esta ciudad y que disponia de estrechas vinculaciones familiares en el Pais Valenciano ${ }^{38}$. Sin embargo, a partir de finales de 1777 se empezaron a realizar también remesas a Pedro Fartané, que, según consta en su correspondencia, era socio de la compañia de Lostau, pero en 1779 se separó de ella para constituir una nueva sociedad con Jaime Fernandez el menor, un conocido comerciante sedero valenciano ${ }^{34}$. Estas operaciones debieron de deteriorar las relaciones de la compañía con Lostau, quien dio por finalizados sus servicios a ésta el 31 de mayo de 1779, quedandose a partir de entonces Fartané como su corresponsal exclusivo en Cádiz. Sin embargo, a partir de 1782 se reanudaron los negocios con Lostau, que compartió con Fartané las consignaciones hasta 1784. Sólo entonces se recurrió a un nuevo corresponsal, Manuel Francisco de la Torre, de origen valenciano, que concentró las operaciones de la compañia en su etapa final. Por tanto, los corresponsales a los que recurrió la compañia en Cádiz fueron escasos y muy conocidos en el mundo de los negocios valenciano de la época, lo que reflejaba la importancia de las relaciones de confianza en las operaciones de esta indole.

Las remesas de los tejidos a Cádiz se realizaban por via terrestre, utilizando el servicio de transporte gestionado por los arrieros valencianos que gozaba ya de un cierto prestigio a nivel peninsular. Comparando las fechas de remisión que figuran en los libros de facturas con las de recepción anotadas en las cuentas de venta, se puede estimar que el trayecto solia efectuarse en un plazo de entre 20 y 25 dias, aunque en algún caso la duración se extendió hasta los 31 dias "1". Sin embargo, lo más importante es que, teniendo en cuenta el esca-

"Los libros de facturas, en A.C.A.M.S.V. Sig. 2.3.1. Libro 4; Sig. 3.4.3. Leg. 29. Las cuentas de venta, en la Sig. 3.4.3. Legs. 88-98. La correspondencia, en la Sig. 3.4.4. Legs 4 y 8 . Por su parte, los li. bros de venta de tejidos en el almacén de Valencia se hallan en la Sig. 2.3.2. Libros 3, 4, 5, 7. 9 y 10.

"Franch (1991), pp. 77.78.

34 A.C.A.M.S.V. Sig. 3.4.4. Leg. 8. Exp. num. 4. Ver carta de 19-11-1779.

11) Fstos extremos sólo se han podido reconstruir en las primeras 21 remesas (que comprendian 241 piezas de tejidos de seda) recibidas por Diego Lostau entre el 8.10.1775 y el 16.10. 1777. En 6 de ellas la duración fue de 20 dias; en 3, de 21; en 2, de 19; en 8 se tardo entre 22 y 25 dias; y en 2 , entre 30 y 31 dias. 
so peso y elevado valor de la mercancía transportada, los costes de la operación tenian una escasa incidencia sobre el precio que ésta alcanzaba en destino. Aquéllos eran satisfechos por el corresponsal gaditano, por lo que quedaban perfectamente reflejados en sus cuentas de venta. $Y$ su análisis ha proporciona. do unos resultados muy concordantes en todos los casos, situando los gastos de remisión entre el $0,70 \%$ y el $0,87 \%$ del valor de las ventas ${ }^{+1}$. Si a ello añadimos los costes de los cajones y del embalaje de los tejidos remitidos (que se han podido conocer en algunos casos y que supusieron alrededor del $0,12 \%$ del valor de venta), se puede afirmar con cierta rotundidad que los costes totales de la remisión de los tejidos raramente superarian el 1 \% de su valor en destino. Sólo teniendo en cuenta esta escasa incidencia podemos comprender que los comerciantes sederos valencianos, a pesar de residir en una ciudad maritima, recurrieran a un medio de transporte que resultaba tan prohibitivo para la mayor parte de las mercancias en el Antiguo Régimen ${ }^{42}$. Además de los gastos aludidos, la comercialización de los tejidos de seda en Cádiz requería también el abono de la comisión que percibia el corresponsal por gestionar las ventas. Durante la segunda mitad del siglo xvill esta se estipulaba en el $3 \%$ cuando no conllevaba ninguna responsabilidad en la percepción de los créditos que se pudieran derivar de la operación, y se elevaba al $5 \%$ si se garantizaba su abono. Esta opción más conservadora es la que adoptó la compañia en todas sus operaciones.

La evolución de las ventas de tejidos de seda en Cádiz se conoce perfectamente gracias a la conservación de la totalidad de las cuentas de venta remitidas por los corresponsales, y sus datos se han plasmado en el cuadro n. ${ }^{\circ} 5$. Su análisis permite comprobar el rápido crecimiento que experimentaron las operaciones en los primeros años de actividad, culminando en las 12.430 varas valencianas comercializadas en 1778 . El estallido de la guerra contra Inglaterra en 1779 interrumpió claramente la tendencia, paralizando prácticamente las operaciones en el año 1780 , en el que sólo se vendieron 758,75 varas valencianas. Pero en 1781 ya se inició una evidente recuperación, que dio paso a la intensa actividad desplegada entre 1782 y 1784 . Estos tres años fueron el perio-

" Entre 1776 y 1779 Lostau incluyó en sus cuentas de venta 3.868 reales de plata como gastos por la recepción de 393 piezas de tejidos de seda. lo que represento el 0,87 o del valor de sus ventas. Por su parte, los $6.218,87$ reales de plata anotados como gastos de recepción por Far. tane entre 1778 y 1784 representaron el $0,830_{0}^{\prime}$ del valor de sus ventas. Y entre 1782 y 1784 los gastos de Lostau por el mismo capitulo se elevaron a 2.184 .49 reales de plata, que representaban el $0,70 \%$ del valor de sus ventas.

$\$ 2$ Para las restantes fibras textiles, por ejemplo, Ringrose y La Force calculan en un $10 \%$ la incidencia del transporte terrestre. Ver Ringrose (1972), pp. 114. La proporcion del $1 \%$ aproximadamente como el coste del transporte de los tejidos de seda desde Valencia a Cádiz se halla documentado tambien a partir de otras fuentes de diversa naturaleza. Ver Franch (1991), p. 80. 
do en el que las ventas de la compañia en Cádiz alcanzaron sus niveles más elevados, hasta el punto de que en ellos se concentró el $56,57 \%$ del valor total de los tejidos comercializados entre 1776 y 1785. Se enmarcan claramente en el periodo de euforia que experimentó el comercio español con América tras la firma de la paz de Versalles y que dio lugar a una cierta saturación del mercado que conduciría a la crisis de $1787^{43}$. No obstante, en nuestro caso aquella expansión se vio bruscamente interrumpida por el proceso de liquidación de la compañia que tuvo lugar en 1785. En conjunto, durante los diez años en que la compañía comercializó sus tejidos en Cádiz, se vendieron un total de 78.393,38 varas valencianas, además de 611 cortes de saya. Debido al distinto sistema de medida que se utilizaba en Castilla, los mismos tejidos alcanzaron en Cádiz una extensión de 83.099,85 varas; es decir, la cantidad se incrementaba en un $6 \%$, lo que constituía una de las bases para la obtención de beneficios en la operación. Y su valor de venta alcanzó los 1.654 .864 reales de plata, lo que equivalia a unas 206.858 libras valencianas. De entre los tipos de tejidos comercializados, destacan el terciopelo, el raso y el fondo, que concentraban el 50,21\% del valor total de las ventas. El hecho de que dos de estos tres tipos de tejidos (el terciopelo y el fondo) fuesen productos de elevado peso y valor puede reflejar perfectamente el carácter minoritario y elitista que tenia en gran medida la demanda americana de tejidos de seda. El panorama lo completaban otras variedades de tipo intermedio, como el damasco, la musulmana, la saya, el estampado y el tafetán, que, conjuntamente, representaban el $35,39 \%$ del valor total de las ventas.

Las operaciones de venta efectuadas por los corresponsales gaditanos solian tener lugar de una forma muy concentrada en determinados meses del año, lo que indica claramente que dependian del ritmo marcado por la partida de los navios a ultramar ${ }^{44}$. $\mathrm{Y}$, de hecho, si se analiza la identidad de los compradores, se puede apreciar que la gran mayoria de ellos eran comerciantes matriculados en la carrera de Indias. Su identificación resulta bastante compleja, ya que las ventas solian tener una entidad muy modesta: fueron un total de 1.432 , con un valor medio de $1.155,63$ reales de plata. De ahi que el número de compradores fuese también muy elevado, abarcando un total de 218 perso-

4 Delgado (1982).

4t Asi, por ejemplo, durante su primera etapa de vinculación con la compañia, las ventas de Lostau siempre concentraron más del $50 \%$ de su valor anual en un determinado mes, que si en 1776 fue el de junio, en 1777, 1778 y 1779 tuvo lugar en enero. En el caso de las ventas de Fartané, la tendencia es muy parecida, aunque la proporción que alcanza la concentración de las operaciones es más irregular: en 1779 , el $42,17 \%$ de ellas tuvo lugar en abril; en cambio, el mes de marzo fue el más importante en 1780 (cuando se concentraron en el todas las ventas), 1781 (cuando se efectuaron el 66,32\% de las ventas) y 1782 (cuando se hicieron el 44,60\%). 


\section{CUADRO 5}

Evolución de las ventas de tejidos de seda en Cádiz efectuadas por los corresponsales de la Compañia de Nuestra Señora de los Desamparados (extensión en varas, valencianas y castellanas, $y$ valor en reales de plata)

\begin{tabular}{|c|c|c|c|c|}
\hline Año & $N^{\prime}$ cortes & Varas tal. & Varas cast. & Valor \\
\hline 1776 & 108 & $2.510,00$ & $2.661,61$ & 71.550 .45 \\
\hline 1777 & 43 & $4.175,75$ & $4.427,41$ & $95.191,63$ \\
\hline 1778 & 65 & $12.430,00$ & $13.175,29$ & $278.645,34$ \\
\hline 1779 & 43 & $9.836,25$ & $10.428,23$ & $197.519,04$ \\
\hline 1780 & 9 & 758,75 & 804,26 & $15.266,37$ \\
\hline 1781 & 12 & $2.563,75$ & $2.718,10$ & $54.623,58$ \\
\hline 1782 & 148 & $15.688,00$ & $16.626,93$ & $350.682,91$ \\
\hline 1783 & 81 & $11.651,63$ & $12.352,31$ & $226.377,70$ \\
\hline 1784 & 102 & $18.354,25$ & $19.455,22$ & $359.182,35$ \\
\hline 1785 & 0 & 425,00 & 450.49 & $5.824,86$ \\
\hline Total...... & 611 & $78.393,38$ & $83.099,86$ & $1.654 .864,23$ \\
\hline
\end{tabular}

FUENT: Cuentas de venta remitidas por los corresponsales gaditanos. A.C.A.M.S.V. Leg 3.4.3. l.egs. 88.98 .

nas o razones sociales distintas. No obstante 23 de ellas tuvieron una presencia más intensa, puesto que acapararon el $45 \%$ del valor total de las ventas. La mayoría de los componentes de este reducido grupo se han podido localizar en la matricula del Consulado de Cargadores a Indias ${ }^{45}$, lo que revela claramente el destino americano que tendrían sus tejidos. Otro aspecto interesante es el origen vasco de buena parte de aquéllos, como es el caso de los dos principales compradores: José Belaustegui, que adquirió el $5,88 \%$ del valor total de las ventas, y Sebastián de Zumarán, que adquirió el 4,67\%. El mismo origen tenian otros 8 de los principales compradores aludidos. Y, por su importancia cualitativa, cabe destacar la presencia del conde de Reparaz, un comerciante matriculado en la carrera de Indias que fue ennoblecido en 1763 y que adquirio el 2,19\% del valor total de las ventas. Las operaciones solian efectuarse a crédito, siendo muy escasas las que se abonaban al contado. Ahora

${ }^{4}$ De los 23 compradores más importantes, se han localizado 15 inscritos en la matricula del Consulado de Cargadores a Indias. El hecho de que los 8 restantes no aparezcan en ella no im. plica que no participaran en el comercio colonial, ya que pudieron intervenir en el marco de una sociedad comercial o a traves de intermediarios. Una relación de los comerciantes matriculados en la Carrera de Indias puede veise en Ruiz Rivera (1988). Un estudio global de la misma ya fue realizada con anterioridad por (jarcia-Baquero (1976), pp. 455.478. 
bien, un análisis detenido del aplazamiento de pago acordado permite distinguir claramente dos periodos muy distintos: entre 1776 y 1779 la demora no suele ser superior a los seis meses, como se dispone en el $88,33 \%$ del valor total de ias ventas; por el contrario, entre 1780 y 1785 las operaciones a corto plazo son claramente minoritarias (sólo en un $23,28 \%$ del valor de las ventas se acuerda el abono en un plazo no superior a los seis meses), predominando las estipuladas al año $(16,09 \%$ del valor ventas $)$ a los 18 meses $(36,29 \% \mathrm{del}$ valor ventas), y llegándose a vincular a la llegada de los caudales de Indias en bastantes casos ( $7,5 \%$ del valor ventas). Seguramente, este incremento de la demora en el pago se derivó de la escasez de numerario que existió en Cádiz tras la larga interrupción del tráfico experimentada durante la guerra contra Inglaterra. En todo caso, permite deducir que la euforia que se produjo tras la firma de la paz de Versalles se sustentó en gran medida sobre el crédito, teniendo, por tanto, unas bases más débiles que las sólidas operaciones al contado o a corto plazo que predominaban con anterioridad.

Los resultados obtenidos con la comercialización de los tejidos en Cádiz se han podido conocer en gran medida por medio de un laborioso trabajo de entrecruzamiento de datos entre el libro diario de piezas fabricadas por la compañía y las cuentas de venta remitidas por los corresponsales ${ }^{40}$. Su distribucion anual se ha plasmado en el cuadro n." 6 , en el que puede apreciarse que los datos más representativos son los correspondientes a los años 1776 1781, ya que abarcan a más del $97 \%$ del valor total de las ventas, llegándose en tres casos al $100 \%$. La representatividad es menor a partir de 1782, aunque sólo desciende del $50 \%$ del valor de las ventas en 1784 . A nivel global, el beneficio medio obtenido se sitúa en el $22,96 \%$. No obstante, la tasa anual llega a alcanzar el $30,34 \%$ en 1776 , y la tendencia parece describir un movimiento ligeramente descendente que alcanzaria su nivel más bajo en 1782, para remontar ligeramente en los dos años posteriores. Quizá la baja tasa de 1782 se derivó de la intensa oferta que se produjo entonces con el fin de dar salida a los tejidos paralizados como consecuencia de la guerra en los dos años anterio-

th En el libro diario de piezas tabricadas se indicaba el coste de produccion de cada una de las piezas y, cuando su descino era Cadiz, se especificaba el nombre del corresponsal al que se di. rigia y el numero de orden que se le habia asignado en la factura. Este último aspecto también se especificaba en las cuentas de venta, lo que facilita la identificación de cada una de aquéllas y la comparación entre cl valor de origen y su precio final de venta. No obstante, la correspondencia es muy intensa en los primeros años de actividad, pero se va debilitando a medida que transcu. rre el tiempo debido al trasvase de piezas entre los corresponsales gaditanos y a la simple remision de tejidos que en un principio se destinaron a los almacenes. De todas formas, la comparacion ha resultado posible para el $78,14 \%$ del valor total de las ventas, lo que otorga un alto indice de fiabilidad a los resultados obtenidos. 
res. En todo caso, si exceptuamos dicho resultado y excluimos también el $30 \%$ de 1776, se puede afirmar que el beneficio habitual solia oscilar entre el $22 \mathrm{y}$ el $26 \%$. Cabe precisar que nos estamos refiriendo a beneficios brutos, de los que habría que deducir, al menos, los costes de remisión y la comisión percibida por los corresponsales, a los que se ha aludido con anterioridad. Pero estas tasas se corresponden bastante con los resultados obtenidos a partir de otras fuentes de diversa naturaleza ${ }^{+8}$, lo que les otorga un mayor grado de fiabilidad.

\section{CUADRO 6}

Evolución de los beneficios derivados de las ventas de tejtdos de seda realizadas en Cádiz por los corresponsales de la Compañia de Nuestra Señora de los Desamparados (valores expresados en libras valencianas)

\begin{tabular}{|c|c|c|c|c|}
\hline Año & Val orig. & Val dest & $o_{\text {teventas tot }}$ & "tibenef \\
\hline 1776 & $6.861,96$ & $8.943,81$ & 100,00 & 30,34 \\
\hline $1777 \ldots$ & $9.409,06$ & $11.898,95$ & 100,00 & 26,46 \\
\hline $1778 \ldots$ & $28.039,54$ & $34.347,97$ & 98,61 & 22,50 \\
\hline 1779 & $19.449,56$ & $24.174,06$ & 97,91 & 24,29 \\
\hline 1780 & $1.515,45$ & $1.908,30$ & 100,00 & 25,92 \\
\hline 1781. & $5.492,53$ & $6.740,76$ & 98,72 & 22,73 \\
\hline 1782. & $31.094,89$ & $37.296,38$ & 85,08 & 19,94 \\
\hline $1783 \ldots$ & $13.245,86$ & $16.219,30$ & 57,32 & 22,45 \\
\hline $1784 \ldots$ & $16.350,88$ & $20.111,63$ & 44,79 & 23,00 \\
\hline Total. & $131.459,73$ & $161.641,16$ & 78,14 & 22,96 \\
\hline
\end{tabular}

FtI:NTF: Cruce de información entre los libros diarios de piezas trabajadas y las cuentas de venta remitidas por los corresponsales gaditanos. Ver las referencias en los cuadros 4 y 5 .

Ii Una conclusion similar se puede obtener agrupando las operaciones globales efectuadas por los diversos corresponsales, que darian los siguientes resultados: entre 1776 y 1779 las ventas de Lostau reportaron un beneficio medio del $24,40 \%$; , en su segunda etapa, entre 1782 y 1784 la tasa se situo en el $23,13 \%$; por su parte. las ventas efectuadas por Fartane entre 1778 y 1784 dieron un beneticio medio del $21,95 \%$.

* Asi, el análisis de los negocios de diversas dinastias sederas a través de documentacion no tarial ha permitido fijar el beneficio empresarial en torno al $15 \%$, al que se añadiría otra tasa adicional de entre el 10 y el 15 of que se derivaria de la ulterior comercialización de los tejidos a Cadiz. Franch (1989 a). Ver, sobre todo, el cuadro de las pags. 230.231. Por su parte, en una carta que el propio Lostau remitio al comerciante valenciano Mariano Canet en 1784 se afirmaba que los altos precios alcanzados entonces por la materia prima reduciria las ganancias desde el 22 al $25 \%$ que se conseguian con arterioridad hasta situarlas entre el 15 y el $20 \%$. Ver Ardit (1982) pp. 170-171 
Obteniendo una rentabilidad tan atractiva, parece bastante lógico que la compañia no se arriesgase a remitir por su propia cuenta los tejidos al merca. do americano; y más teniendo en cuenta que en las pocas ocasiones en que se aventuró a hacerlo obtuvo unos resultados muy poco satisfactorios. En la documentación consultada, sólo se ha encontrado constancia de dos operaciones de dicha indole. La primera fue muy modesta, y tuvo lugar en 1777 , cuando se embarcaron en la fragata "San Joseph», alias «el Coro», con destino a Cartagena de Indias, 274,80 varas castellanas de espolin y moaré. Su valor a precios de Espana ascendia a 4.940,5 reales de plata, y se vendieron en Cartagena de Indias con un beneficio bruto del $12 \%$ y un aplazamiento del pago de 18 meses. Sin embargo, los gastos, entre los que se incluyó la negociación del crédito (a razón del $10 \%$ anual) para recuperar inmediatamente el producto de la venta, acabaron superando a los beneficios, y la operación se saldó con una pérdida del $3,32 \%$ del valor inicial de la remesa a precios de España t9. Escarmentada, quizá, ante este resultado, la compañia no volvió a realizar una nueva tentativa hasta que se vio forzada a ello por la paralización del tráfico como consecuencia de la guerra contra Inglaterra. La escasa «salida» que tenian los tejidos en Cádiz la impulsó a cargar en el convoy que se organizó en la primavera de 1780 diversas piezas por un valor total, incluidos los gastos de embarque y la comisión, de 40.747,12 reales de plata. En su mayor parte se remitieron a Veracruz, aunque en dos buques distintos: en el navio «El Gallardo» se cargaron efectos por valor de 27.120,90 reales de plata; y en el navío «San Francisco de Paula» la remesa ascendió a $3.948,93$ reales de plata. La operación se completó con el cargamento por valor de $9.677,25$ reales de plata en el navio «Nuestra Señora del Pilar» con destino a Buenos Aires. A pesar de la peligrosidad del momento, la compañía acordó no asegurar la mercancía, disponiendo, en cambio, que a su llegada a América se destinaria la cuarta parte del posible valor de la póliza a la realización de misas en honor de los patrones de la sociedad ${ }^{50}$. Y esta decisión resultó muy negativa, ya que el navio que llevaba la remesa más valiosa («El Gallardo») naufrago en Puerto Rico ${ }^{51}$. De las otras dos operaciones, sólo la menos elevada reportó un beneficio liquido bastante atractivo, del orden del $43,60 \%$ del coste de la remesa, aunque hubo algunos problemas para recuperar integramente la totalidad del capital. En cambio, el producto de los tejidos que se vendieron en Buenos Aires fue invertido por el destinatario en la adquisición de 1.496 cueros, y su comercialización ulterior en Cádiz acabó saldando definitivamente la operación con unas ganancias del

ty Ver la cuenta de venta en A.C.A.M.S.V. Sig. 3.4.3. Leg. 89.

so A.C.A.M.S.V. Sig. 2.3.1. Libro 21. Ver deliberación de 11.5-1780.

"Ribes (1985), p. 87. 
$1,51 \%$ del valor inicial de la remesa. Además, el capital sólo se logró recuperar al cabo de algo más de cuatro años desde que se inició la operación ${ }^{52}$. El balance de la intervención directa de la compañia en el comercio americano no podía ser, pues, más decepcionante. La falta de experiencia y de una infraestructura propia determinaba que los elevados beneficios que se podian obtener en este tráfico se evaporasen en gran medida debido al pago de innumerables comisiones, de primas en el cobro anticipado de los créditos y de gastos de todo tipo, sufriendo, además, largas demoras en la recuperación de la inversión. De ahi que resultara más sensato limitar el negocio a la comercialización de los tejidos en Cádiz, en donde se solian obtener unos beneficios bas. tante seguros y atractivos, y dejar que fuesen los cargadores de Indias los que, aprovechando su dominio de la carrera, se encargaran de conducir el producto al mercado americano. Esta actitud es la que adoptó también la mayor parte de los comerciantes sederos valencianos de la época.

Aparte del negocio efectuado con la venta de tejidos de seda, el comercio con Cádiz podia proporcionar un beneficio adicional mediante la inversión del capital en productos coloniales para su ulterior comercialización en Valencia. Sin embargo, la Compañia de Nuestra Señora de los Desamparados efectuó muy pocas veces este tipo de operaciones, siendo sólo más frecuentes en los primeros años de actividad ${ }^{33}$. En estos casos, el cacao y el azúcar eran las mercancias que tenían un predominio abrumador, completando el panorama algunas pequeñas remesas de grana y de otros productos no especificados. Algunas operaciones se realizaron con una participación del corresponsal gaditano en el $50 \%$ del resultado del negocio, lo que ha permitido conocer los beneficios obtenidos al especificarse la cantidad que le correspondia en su cuenta corriente. A partir de las ocho operaciones en que se produce este hecho, se puede deducir que la venta de azúcar podia reportar un beneficio cifrado entre el 13 y el $15 \%$, mientras que en cl caso del cacao los resultados se situaban entre el 4 y el $7 \%$, llegando en una ocasión a limitarse al $1,99 \%$. De todas formas, parece que la compañia carecia de experiencia y de una adecuada infraestructura para la comercialización de los productos coloniales, por lo que acabó

9 Las facturas y cuentas de venta de estas remesas de 1780 a América se hallan en A.C.A.M.S.V. Sig. 3.4.3. Legs. $91,92,94$ y 95.

"Asi, en las remesas efectuadas por Lostau desde Cadiz entre 1776 y 1779 las mercancias llegaron a constituir el 43,31\% del valor total; mientras que en las realizadas por Fartané entre 1778 y 1784 sólo representaron el $5,16 \%$; no teniendo ninguna presencia en la segunda etapa de Lostau (1782-84) y en las operaciones de Manuel Francisco de la Torre (1784.85).

"Los resultados concretos son los siguientes: en octubre de 1777 se obtuvo en la venta de 30 cajas de azúcar el 14,84\%; en octubre de 1778 otra partida de 30 cajas de azúcar produjo el $13,05 \%$; en febrero de 1777 se obtuvo en la venta de 15 sacos de cacao el 4,91\%; en octubre de 
abandonando este negocio. De ahi que los corresponsales gaditanos remitiesen cada vez con mayor frecuencia dinero en efectivo para reintegrar a la compañía el producto de sus ventas. No obstante, en la década de 1780 la situación se complicó con la puesta en circulación de los vales reales. Y fue concretamente la pretensión de Fartané en noviembre de 1784 de cobrar 7.527,62 reales de plata por «... quebranto en la reducción de villetes a efectivo...» por un montante total de $322.713,25$ reales de plata (lo que suponia una penalización del $2,33 \%$, lo que provocó un grave conflicto que acabaria determinando la ruptura de sus relaciones con la compañia ${ }^{55}$. La liquidación definitiva de cuentas, tanto en este caso como en el del resto de los corresponsales gaditanos, se complicó debido a la existencia de numerosos pagarés derivados de la venta de tejidos con largos aplazamientos del pago, procedimiento muy frecuente en este periodo como se ha señalado anteriormente.

\section{BIBLIOGRAFÍA}

AkirT, M. (1982): «Datos sobre el comercio español con América en el siglo xvill. Las empresas comerciales de Mariano Canet y Montalbán (1758-1785)". Estudios dedicados a Juan Peset Aleixandre. Valencia, pp. 157-174.

Catala Sanz, I. A. (1995): Rentas y patrimonios de la nobleza valenciana en el siglo XVHII. Madrid.

Delgado Ribas, J. M. (1982): «El impacto de las crisis coloniales en la economia catalana (1787-1807)m. La economía española al final del Antiguo Régimen. III. Comercio y colonias. Madrid, pp. 99-169.

DIEZ, F. (1992): «La crisis gremial y los problemas de la sederia valenciana (finales del siglo xvill y principios del siglo xix)m. Revista de Historia Económica, año X, núm. 1, pp. 39-61.

Chaussinand-Nogiaret, G. (1984): La noblesse au xville. siècle. De la feodalité aux lumières. Paris.

FRANCH, R. (1986): Crecimiento comercial y enriquecimiento burgués en la Valencia del siglo X'III. Valencia.

- (1989 a): El capital comercial valenciano en el siglo xi'm. Valencia.

- (1989 b): «La política de liberalización económica de Carlos III y la materia prima sedera valencianam. Estudis-14. Valencia, pp. 51-81.

1777 con 20 sacos de cacao el beneficio fue del $6,04 \%$; en marzo de 1778 se obtuvo con otros 20 sacos de cacao el $1,99 \%$; en octubre de 1778 con 30 sacos de cacao el beneficio fue del $6,65 \%$; en febrero de 1777 se obtuvo el $6,83 \%$ en la venta de 6 sacos de cacao y 18 cajas de azucar; y en febrero de 1779 el beneficio fue del 4,62\% en la venta de 10 sacos de cacao y de 15 cajas de azúcar. Todo ello consta en el correspondiente «debe" de los resúmenes de la cuenta corriente remitidos por Lostau. A.C.A.M.S.V. Sig. 3.4.3. Legs. 88-91.

"La compañia no admitio aquel cargo, eliminandolo en su propuesta de liquidación de cuentas fechada el 31-10-1785. A.C.A.M.S.V. Sig. 3.4.3. Leg. 96-97. 
(1990): «La comercialización de la seda valenciana a finales del Antiguo Régimen: el "contraste» de la ciudad de Valencia». Revista de Historia Económica, año VIII, núm. 2, pp, 271.304.

(1991): «La atracción de los mercados andaluz y colonial sobre el comercio valen. ciano dieciochescom. La burguesía de negocios en la Andalucia de la Ilustración. Cadiz, tomo I, pp. 71-83.

(1994 a): «El comerç valencià amb Amèrica al segle xv'ulı. Una relació de caràcter indirecte». Afers, núm. 19. Catarroja, pp. 639-658.

- (1994 b): «La producción de seda en el Pais Valenciano durante el siglo xvirl: distribución geográfica y evolución». Noticiario de Historia Agraria, núm. 8, Murcia, pp. 67-98.

Garcia-Baqurero, A. (1976): Cádiz y el Atlántico (1717-1778). Sevilla.

Gakcia SANZ, A. (1977): Desarrollo y crisis del Antiguo Régimen en Castilla la Vieja. Economia y sociculad en tierras de Segovia (1500-1814). Madrid.

LAPAYF.SE, ]. (1779): Tratado del arte de bilar, devanar, doblar y torcer las sedas según el métado de Mr. Vaucanson, con algunas adiciones y correcciones a él. Madrid.

Martinlz SANTos, V. (1981): Cara y cruz de la sedería valenciana (siglos XIIII-XIX). Valencia.

Pa.op, J. M. (1977): Hambre y lucha antifeudal. Las crisis de subsistencias en Valencia (siglo Xi'iI). Valencia.

Rires Iborka, V. (1985): Los valencianos y América. El comercio valenciano con Indias en el siglo xim. Valencia.

Richard), G. (1974): Noblesse d'affaires au ximli: siécle, Paris.

RiNciRose., D. (1972): Los transportes y el estancamiento económico de España (1750-1850). Madrid.

Ruiz. Rivera, J. B. (1988): El Consulado de Cádiz. Matrícula de comerciantes (1730-1823) Cadiz.

VII)Al y Polo, J. M. (1862): Tablas de reducción de las antiguas medidas, pesos y monedas al nuevo sistema métrico decimal. Valencia. 